\title{
Identifikasi Marka Bioakustik Suara Kokok Ayam Kokok Balenggek di Kandang Penangkaran "Agutalok", Kabupaten Solok
}

\author{
Identification of Bioacoustic Marker of Kokok Balenggek Song Fowl \\ Inside A Captive Breeding Farm in "Agutalok" Solok Regency, Indonesia
}

\author{
Rusfidra, Y.Y. Tumatra, M.H. Abbas, Y. Heryandi, dan F. Arlina \\ Fakultas Peternakan Universitas Andalas \\ Kampus Unand Limau Manis Padang, 25163 \\ e-mail: rusfidra@gmail.com
}

(Diterima: 1 November 2011; Disetujui: 27 Januari 2012)

\begin{abstract}
Kokok Balenggek chicken is a genetic resources from West Sumatra Province, Indonesia, well known as song fowl which has high economic commodity for Minang Kabau tribes. There is an important need to identify bioacoustic marker of Kokok Balenggek song fowl in Solok regency of West Sumatra, Indonesia. This research was aimed to collect basic data of crow characteristics of Kokok Balenggek song fowl. This research was conducted in a captive breeding farm "Agutalok", Solok Regency, Indonesia. The number of 21 heads of adult male Kokok Balenggek chicken were selected as samples in this project. Song characteristics of Kokok Balenggek chicken was observed using time sampling method. Time observation was performed in three time period; Morning (4-6 a.m), Noon (11 a.m-1 p.m) and Afternoon (4-6 p.m) for three days consecutively. Some parameters such as number of crows, number of phrase crows, time of crows, duration of crows, and frequency of crows were recorded during the observation. The results showed that the number of crows were ranging 5-11 crows, number of phrases crow were 8-14 phrases, time of crows were happened more frequent in the morning, duration of crows were 3.22 seconds happened frequently at Noon with frequency of crows were 9.39 times/10 minutes.
\end{abstract}

Keywords: Kokok Balenggek chicken, crow, bioacoustics, Solok Regency-Indonesia

\section{PENDAHULUAN}

Ayam kokok balenggek (AKB) merupakan sumber daya genetik "ayam penyanyi" di Sumatera Barat (Rusfidra, 2004; Rusfidra, 2006, Rusfidra, 2007; Rusfidra et al., 2009; Rusfidra et al., 2010). AKB memiliki suara kokok merdu dan bersusun-susun (dapat mencapai 24 suku kata) (balenggek: bahasa Minang). Kemerduan dan keunikan suara kokok AKB diduga satu-satunya bangsa ayam dengan tipe kokok balenggek di dunia (Rusfidra, 2004). Itu sebabnya AKB memiliki posisi yang tinggi bagi masyarakat suku Minangkabau (Fumihito et al., 1996). Berdasarkan Surat Keputusan Menteri Pertanian No: 2919/Kpts/OT.140/6/2011, ayam Kokok Balenggek telah ditetapkan sebagai rumpun ternak nasional.

Berdasarkan penelusuran literatur ilmiah, AKB diduga merupakan turunan per- silangan ayam Hutan Merah (Gallus gallus) dengan ayam lokal daerah sentra. Dugaan ini di dasarkan pada teori bahwa hanya G. gallus yang terdapat di pulau Sumatera (Nishida et al., 1982, Fumihito et al., 1994). Selain itu, Weigend dan Romanof (2001) menyatakan bahwa G. gallus merupakan nenek moyang dari semua bangsa ayam domestik yang berkembang sekarang.

Ayam kokok balenggek merupakan tipe "ayam penyanyi" yang memiliki suara kokok merdu, bersusun-susun dan enak didengar (Rusfidra, 2004). Suara kokoknya sangat khas. Masyarakat daerah sentra menamakannya ayam kokok balenggek (Abbas et al., 1997). Rusfidra (2004) mengelompokkan suku kata kokok AKB menjadi tiga bagian, yaitu kokok depan, kokok tengah dan kokok belakang. Kokok depan dimulai dari suku kata pertama, kokok tengah terdiri dari suku kata kokok kedua dan ketiga, dan kokok belakang dihi- 
tung dari suku kata keempat sampai suku kata terakhir. Kokok bagian belakang disebut lenggek kokok. Jumlah lenggek kokok dihitung berdasarkan pengurangan jumlah suku kata kokok dengan tiga poin.

Suku kata kokok adalah suara kokok yang mengelompok dalam sebuah kelompok suara yang rapat dan antara suku kata terdapat fragmentasi yang jelas. JSK AKB berkisar dari enam sampai 12 suku kata, dengan rataan 8,07 suku kata. JSK sangat penting dalam pelaksanaan kontes dan penentuan harga jual AKB. Semakin banyak JSK, maka semakin tinggi harga jual AKB dan semakin besar peluang memenangkan kontes suara kokok (Rusfidra, 2004; Rusfidra et al., 2009).

Jumlah lenggek kokok dihitung dengan mengurangi total suku kata kokok dengan tiga poin. JLK AKB berkisar dari 3-9 lenggek dengan rataan 5,07. Perbedaan JLK antar AKB diduga sebagai bentuk variasi individu. JLK sangat penting dalam pelaksanaan kontes dan penentuan harga jual AKB. Semakin banyak JLK, maka semakin tinggi harga jual AKB (Rusfidra, 2004).

Rataan durasi kokok AKB adalah 3,018 detik, dengan kisaran 2,088-4,431 detik (Rusfidra, 2004), tidak jauh berbeda dengan durasi kokok ayam domestik 2-3 detik (Siegel dan Dunnington, 1990). Durasi kokok AKB lebih pendek dari kokok ayam pelung, ayam toutenko, toumaru dan koeyoshi. Ayam pelung umur 11 bulan memiliki durasi kokok 3,0-8,9 detik (Jatmiko, 2001). Durasi kokok AKB dapat dijadikan sebagai kriteria seleksi pejantan AKB dalam untuk pengembangan tipe "ayam penyanyi". Rusfidra (2004) menyatakan bahwa durasi dan frekuensi berkokok dapat dijadikan sebagai kriteria seleksi ayam jantan berkokok merdu.

Durasi berkokok lebih lama terjadi pagi hari (pukul 06.00-08.00 WIB) dengan rataan 3,096 detik pada AKB, diikuti sore hari (pukul 15.00-17.00 WIB), dan siang hari (pukul 11.00-13.00 WIB) dengan durasi kokok masing-masing 3,075 dan 2,883 detik. Puncak aktivitas berkokok terjadi pada pagi hari (Rusfidra, 2004).

Frekuensi berkokok penting diketahui karena sifat ini termasuk salah satu unsur yang dinilai pada kontes AKB. Rataan frekuensi berkokok AKB adalah 8,08 kali/10 menit. Aktivitas puncak berkokok AKB terjadi pada pagi hari (9,59 kali), diikuti sore hari (7,62 kali) dan siang hari (7,02 kali) (Rusfidra, 2004).

Saat ini di daerah sentra populasi AKB makin berkurang karena banyak AKB yang dijual keluar daerah sentra, bahkan AKB yang memiliki suara kokok ayam panjang (banyak lenggek) sudah jarang dijumpai di daerah asalnya di Kecamatan Tigo Lurah, Kabupaten Solok. Selain itu, populasi AKB menurun drastis karena serangan penyakit ND (Newcastle disease) serta kurangnya kontes AKB. Berdasarkan kondisi tersebut, maka perlu dilakukan upaya-upaya untuk menjaga kelestarian AKB agar tidak punah, baik konservasi di daerah sentra (in-situ), maupun di luar daerah sentra (ek-situ).

AKB merupakan sumber daya genetik unggas Indonesia yang perlu dipertahankan kemurnian dan kelestariannya. Adanya variasi genetik yang tinggi pada AKB menunjukkan adanya potensi untuk perbaikan mutu genetik. Untuk itu diperlukan data-data dasar mengenai marka suara kokok AKB di daerah konservasi ek-situ.

Usaha peternakan "Agutalok" Kabupaten Solok merupakan salah satu kandang penangkaran AKB secara ek-situ. Usaha peternakan "Agutalok" telah memelihara dan mengembangkan AKB sejak tahun 1994 sampai sekarang. Berdasarkan kondisi diatas maka rumusan masalah penelitian adalah bagaimana performa suara kokok AKB pada kandang penangkaran Agutalok Kabupaten Solok.

Tujuan penelitian adalah memperoleh data dasar marka suara kokok AKB di kandang penangkaran $e k$-situ Agutalok.

\section{METODE}

Materi yang digunakan dalam penelitian ini adalah 21 ekor Ayam Kokok Balenggek jantan dewasa (sudah berkokok). Peralatan yang digunakan dalam penelitian ini adalah kamera digital dan timer. 
Penelitian ini dilakukan dengan metode survei dan pengamatan secara langsung terhadap suara kokok AKB pada kandang penangkaran Agutalok Kabupaten Solok. Karakterisasi suara kokok ditetapkan menggunakan metode time sampling (Rusfidra, 2004). ini adalah:

Parameter yang diamati pada penelitian

a. Jumlah lenggek kokok (JLK)

b. Jumlah suku kata kokok (JSK)

c. Waktu berkokok (WBK)

Mengamati waktu ayam berkokok pada 10 kali ayam berkokok berturut-turut pada tiga periode waktu yaitu, pagi (pukul 04.00-06.00 WIB), siang (pukul 11.0013.00 WIB), dan sore (pukul 16.00-18.00 WIB).

d. Durasi kokok (DKK)

Durasi kokok adalah lama waktu berkokok (detik) yang diamati pada 10 kali ayam berkokok berturut-turut pada pagi, siang, dan sore hari.

e. Frekuensi berkokok(FKK)

Frekuensi berkokok adalah tingkat kekerapan ayam berkokok dalam periode waktu 10 menit yang dicatat pada waktu pagi, siang, dan sore selama tiga hari berturut-turut, yaitu hari pertama (H1), hari kedua $(\mathrm{H} 2)$ dan hari ketiga $(\mathrm{H} 3)$.

Data suara kokok AKB yang terkumpul ditabulasi, dihitung nilai rataan, standar deviasi dan kisarannya (Rusfidra, 2004).

Penelitian ini dilakukan pada usaha peternakan AKB Agutalok di Nagari Guguak Kabupaten Solok. Penelitian berlangsung dari tanggal 23 Agustus 2010 sampai 23 Oktober 2010 .

\section{HASIL DAN PEMBAHASAN}

\section{Kondisi Kandang Penangkaran AKB di Agutalok}

Usaha peternakan Agutalok (Ayam Kukuak Balenggek Gunung Talang Solok) terdapat di Nagari Guguak, Kecamatan Gunuang Talang, Kabupaten Solok. Disini AKB dipelihara di dalam kandang individu di pekarangan rumah pemilik AKB. Usaha peternakan Agutalok berdiri pada tahun 1994 yang bermula dari hobi memelihara AKB sebanyak 10 ekor dan pernah mencapai 100 ekor AKB. Namun pada saat sekarang karena jumlah populasi AKB yang semakin berkurang di daerah sentra dan permintaan konsumen yang tinggi menyebabkan jumlah AKB di Agutalok hanya 21 ekor AKB jantan dewasa.

Usaha peternakan Agutalok bertujuan mempertahankan populasi AKB tetap lestari. $\mathrm{AKB}$ diperoleh dengan jalan membeli pada peternak dari daerah sentra AKB berasal dari daerah sentra yaitu Kapujan, Batu Bajanjang, Garabak Data, Dilam, Limau Lunggo, Sirukam, Sumiso, dan Batu Bajanjang.

Makanan yang diberikan pada AKB terdiri dari padi, jagung, dedak, nasi sisa, sayuran berupa kangkung, rumput banto, dan daun pepaya dengan cara mencampurkan semua bahan tersebut. Sayur diiris dan ditambahkan dengan air secukupnya dan diberikan pada AKB sekali sehari.

\section{Karakteristik Suara Kokok}

Suara kokok AKB sangat khas. Rusfidra (2004) mengelompokkan suku kata kokok AKB menjadi tiga bagian, yaitu kokok depan, kokok tengah dan kokok belakang. Kokok depan dimulai dari suku kata pertama, kokok tengah terdiri dari suku kata kokok kedua dan ketiga, dan kokok belakang dihitung dari suku kata keempat sampai suku kata terakhir. Jumlah lenggek kokok dihitung berdasarkan pengurangan jumlah suku kata kokok dengan tiga poin, misalnya:

1). balenggek tiga: jumlah suku kata enam dikurang tiga,

2). balenggek tujuh: suku kata 10 dikurang tiga.

\section{Jumlah Lenggek Kokok (JLK)}

Jumlah lenggek kokok AKB berkisar dari 5-11 lenggek dengan rataan 6,57 lenggek. JLK AKB di Agutalok lebih banyak dari hasil penelitian Rusfidra (2004) yang menyatakan bahwa JLK AKB berkisar dari 3-9 lenggek dengan rataan 5,07 lenggek. JLK sangat penting dalam pelaksanaan kontes dan penentuan harga jual AKB. Semakin banyak JLK, maka semakin tinggi harga jual AKB. Berbedanya 
JLK antara hasil penelitian di Agutalok dengan penelitian Rusfidra (2004) adalah karena peternak Agutalok melakukan seleksi terhadap AKB yang memiliki JLK banyak berdasarkan permintaan konsumen yang cenderung menyukai AKB yang banyak JLK-nya dengan kisaran 5-11 lenggek, sementara Rusfidra (2004) melakukan penelitian di daerah in-situ.

\section{Jumlah Suku Kata Kokok (JSK)}

Rataan jumlah suku kata AKB di Agutalok adalah 8 - 14 suku kata dengan rataan 9,57 suku kata. JSK AKB di Agutalok lebih banyak dari penelitian Rusfidra (2004) yang menyatakan bahwa JSK AKB berkisar dari 6 - 12 suku kata, dengan rataan 8,07 suku kata. JSK sangat penting dalam pelaksanaan kontes dan penentuan harga jual AKB. Semakin banyak JSK, maka semakin tinggi harga jual AKB dan semakin besar peluang memenangkan kontes suara kokok AKB di Sumatera Barat (Rusfidra, 2004).

\section{Waktu Berkokok (WKK)}

Waktu berkokok pada AKB yang diamati terjadi pada tiga periode waktu, yaitu pagi hari (pukul 04:08 - 05:58 WIB), siang hari (pukul 11:00 - 13:00 WIB) dan sore hari (pukul 16:00-17:58 WIB). WKK AKB di Agutalok lebih panjang dari penelitian Rusfidra (2004) yang menyatakan bahwa durasi berkokok lebih lama terjadi pagi hari (pukul 06.00-08.00 WIB) dengan rataan 3,096 detik, diikuti sore hari (pukul 15.00-17.00 WIB), dan siang hari (pukul 11.00-13.00 WIB) dengan durasi kokok masing-masing 3,075 dan 2,883 detik. Puncak aktivitas berkokok terjadi pada pagi hari.

\section{Durasi Berkokok (DKK)}

Rataan durasi kokok AKB adalah 3,22 detik, dengan kisaran 2,00-4,90 detik. Durasi kokok lebih lama terjadi pada siang hari dengan rataan 3,59 detik, diikuti sore hari dengan rataan 3,09 detik, dan pagi hari dengan rataan 2,99 detik. Hasil penelitian ini lebih lama dari hasil penelitian Rusfidra (2004) yang menyatakan bahwa rataan durasi kokok AKB adalah 3,018 detik, dengan kisaran 2,088-4,431 detik, lebih panjang dari durasi kokok ayam domestik 2-3 detik (Siegel dan Dunnington, 1990). Akan tetapi durasi kokok AKB lebih pendek dari kokok ayam pelung. Ayam pelung umur 11 bulan memiliki durasi kokok 3,0-8,9 detik (Jatmiko, 2001). Durasi kokok AKB dapat dijadikan sebagai kriteria seleksi pejantan AKB untuk pengembangan tipe "ayam penyanyi". (Rusfidra, 2004).

\section{Frekuensi Berkokok (FKK)}

Frekuensi berkokok penting diketahui karena sifat ini termasuk salah satu unsur yang dinilai pada kontes AKB. Rataan frekuensi berkokok AKB diAgutalok adalah 9,39 kali/10 menit dengan kisaran frekuensi kokok 4-16 kali/menit.

\section{KESIMPULAN}

1. AKB merupakan sumber daya genetik ayam lokal yang memiliki suara kokok merdu dan enak didengar.

2. Jumlah lenggek kokok AKB di usaha peternakan Agutalok adalah 6,57 lenggek dan jumlah suku kata adalah 9,57 suku kata.

3. Durasi kokok AKB lebih panjang terjadi pada siang hari yaitu selama 3,59 detik, diikuti sore hari 3,09 detik, dan pagi hari 2,99 detik. Rataan durasi kokok AKB secara keseluruhan adalah 3,22 detik.

4. Rataan frekuensi berkokok AKB di Agutalok adalah 9,39 kali/10 menit dengan kisaran frekuensi kokok 4-16 kali/menit.

\section{UCAPAN TERIMAKASIH}

Ucapan terimakasih disampaikan kepada DP2M Ditjen Pendidikan Tinggi atas bantuan biaya penelitian dalam Skim Hibah Bersaing pada Tahun 2009-2010 dengan judul penelitian "Pelestarian plasma nutfah Ayam Kokok Balenggek; Ayam Lokal Sumatera Barat melalui karakterisasi genetik, kajian bioakustik dan apilkasi bioteknologi reproduksi". 


\section{DAFTAR PUSTAKA}

Abbas, M. H, A. Arifin, S. Anwar, A. Agustar, Y. Heryandi dan Zedril. 1997. Studi ayam Kokok Balenggek di Kecamatan Payung Sakaki, Kabupaten Solok: Potensi wilayah dan genetika. [Laporan Penelitian]. Padang: Pusat Pengkajian Peternakan dan Perikanan. Fakultas Peternakan Universitas Andalas-Dinas Peternakan Propinsi Sumatera Barat.

Fumihito, A. et al. 1994. One subspecies of the Red Jungle Fowls (Gallus gallus gallus) suffices as the matriarchic ancestor of all domestic breeds. Proc. Natl. Acad. Sci, USA. 91: 12505-12509 [Abstr.]

Fumihito,. T. Miyake, M. Takada, R. Shingu, M. T. Endo, T. Gojo Baru, N. Kondo, and S. Ohno. 1996. Monophyletic origin and one subspecies of the red jungle fowl (Gallus gallus gallus) dispersal patten of domestic fowl. Proc. Nat. Acad Sci $93: 6792679$.

Jatmiko. 2001. Studi fenotipe ayam Pelung untuk seleksi tipe ayam penyanyi. [Tesis]. Bogor: Institut Pertanian Bogor, Program Pascasarjana.

Kementerian Pertanian. 2011. SK. Menteri Pertanian No.: 2919/Kpts/OT.140/6/ 2011 Tentang Penetapan Ayam Kokok Balenggek sebagai Rumpun Ternak Nasional.

Nishida,T., Y. Hayashi, and K. Kondo. 1980. Ecological and morfological studies on the Red Jungle Fowl and the Green Jungle Fowl in Indonesia. Report of Research Group of Overseas Scientific Survey.

Rusfidra. 2004. Karakterisasi sifat-sifat fenotipik sebagai strategi awal konservasi ayam kokok balenggek di
Sumatera Barat. (Disertasi) (tidak dipublikasikan). Bogor: Sekolah Pascasarjana Institut Pertanian Bogor.

Rusfidra. 2006. Pengembangan riset bioakustik di Indonesia; studi pada ayam kokok balenggek, pelung dan bekisar. Prosiding Seminar Nasional Penelitian dan Pengembangan MIPA di FMIPA Universitas Negeri Yogyakarta, Hotel Inna Garuda, 1 Agustus 2006.

Rusfidra. 2007. Pemanfaatan waveform suara kokok sebagai marker suatu bangsa pada "ayam penyanyi" di Indonesia. Prosiding Seminar Nasional Sains dan Teknologi untuk Kejayaan Bangsa. Bandar Lampung: Lembaga Penelitian Universitas Lampung, 27-28 Agustus 2007.

Rusfidra, M. H. Abbas, Y. Heryandi dan F. Arlina. 2009. Pelestarian plasma nutfah ayam Kokok Balenggek melalui karakterisasi genetik, kajian bioakustik dan aplikasi bioteknologi reproduksi. Laporan Penelitian Hibah Bersaing (Tahun Pertama).

Rusfidra, M. H. Abbas, Y. Heryandi dan F. Arlina. 2010. Pelestarian plasma nutfah ayam Kokok Balenggek melalui karakterisasi genetic, kajian bioakustik dan aplikasi bioteknologi reproduksi. Laporan Penelitian Hibah Bersaing (Tahun Kedua).

Siegel, P. B., and E. A. Dunnington. 1990. Behavioral Genetic. pp: 877-895. In: Crawford, R. D. (ed.). Poultry Breeding and Genetics. 1990. Amsterdam, The Nederlands: Elsevier Sciences Publishers BV.

Weigend, S., and M.N. Romanov. 2001. Current strategies for assesment and evaluation of genetic diversity in chicken resources. World Poultry Science Journal, 57: 275-288. 